\title{
Voiced and Voiceless Alveolar Stops of Kermani Accent in stressed and unstressed syllables
}

\section{Vahideh Abolhasanizadeh, Anis Masoumi}

Assistant Professor of Shahid Bahonar University of Kerman, Department of foreign languages, faculty of literature and humanities, Shahid Bahonar university of Kerman, Pazhuhesh square, Kerman, 7616914111,

vahidehabolhasani@yahoo.com

M.A student of Allame Tabataba'i University of Tehran

anis_masoumi@yahoo.com

\section{ABSTRACT}

This study aims to compare the voiced and voiceless alveolar stops of Kermani accent in stressed and unstressed syllables. Ten subjects with Kermani accent were asked to repeat 2 words and their plurals for three times. These words are minimal pairs and are different in the first phoneme. Also the effect of these phonemes on the F1, F2 and F0 of the following vowel is measured and compared in stressed and unstressed syllables. Results show that the mean VOT of [t] and [d] in stressed position is more than that in unstressed positions. Unlike F2, F0 and F1 of vowels following [t] and [d] in stressed syllables is more than that in unstressed syllables. Also F0 and F2 of vowels following [+voiced] alveolar stops are more than those following [-voiced] alveolar stops.

Keywords: VOT; F0; F1; F2; stressed syllable; unstressed syllable.

\section{Council for Innovative Research}

Peer Review Research Publishing System

Journal: Journal of Advances in Linguistics

vol .5 No 2

editor@cirjal.com

www.cirjal.com, www.cirworld.com 


\section{INTRODUCTION}

Kermani accent is a variety of Persian language spoken in Kerman. Mentioned accent and the Standard Persian accent are different in terms of phonological and lexical aspects. In this study the VOT of the voiced and voiceless alveolar stops of Kermani accent in stressed and unstressed syllables are compared. In addition, the effect of these consonants on the F1, F0 and F2 of the following vowels has been studied. In unstressed syllables, the process of centripetal vowel reduction occurs in Kermani accent and in the conclusion section, the vowel reduction process has been discussed.

\section{LITERATURE REVIEW}

AIDahri (2013) considers VOT as a main feature used to differ between voiced stops and unvoiced stops. VOT is the length time (period) between the onset of voicing pulses and the release of the primary occlusion of the vocal tract. VOT is only relevant for stop consonants and it is measured in milliseconds (ms). Stop consonants are articulated with a closure of the vocal tract in their place of articulation. He classifies VOT in three classifications. There are zero VOT, positive VOT and negative VOT. Zero VOT occurs in case of coincidence of the onset of vocal fold vibration with the plosive release. Positive VOT is the result of a delay in the onset of vocal fold vibration after the plosive release. In negative VOT, the onset of vocal folds vibration precedes the plosive release. He compared and analyzed the voiced/unvoiced /d/ and /t/ and $/ \mathrm{d}$ / and / $\mathrm{t}$ / in Modern standard Arabic. He found that the VOT values for /d/ and /t/ are positive 16 and $51.65 \mathrm{~ms}$, respectively. Unlike Arabic, English voiced stops have negative VOT but in case of unvoiced stops, VOT of both of these languages are positive. Analyzing speakers of three Arabic dialects shows that they vocalize /d/ stops in the same way, but they have big variations of vocalizing the /t/ stop which is an unvoiced stop. Also measuring the VOT of $/ d^{2} /$ and $/ \mathrm{t}$ ? shows that their average VOT is 11.5 and $18.35 \mathrm{~ms}$, respectively. Finally to conclude he found that the VOT of /t/ and / d/ is always more than VOT of $/ \mathrm{d} / \mathrm{and} / \mathrm{t} / \mathrm{a}$ and the VOT of all of them is always positive. Cho and Ladefoged (1999), in their article, mention that: (1) the further back the closure, the longer the VOT (Fischer-Jørgensen, 1954); (2) the more extended the contact area, the longer the VOT (Stevens, Keyser and Kawasaki, 1960); and (3) the faster the movement of the articulator, the shorter the VOT (Hardcastle, 1973). Lisker and Abramson (1964) found that voiceless plosives have a greater articulatory force, or a louder burst, than voiced ones. Another experiment by Lisker and Abramson (1970), showed that tokens were identified as voiced if their VOT durations were under 15,20 , and $30 \mathrm{~ms}$ for $/ \mathrm{b} /, / \mathrm{d} /$, and $/ \mathrm{g} /$, respectively; tokens were identified as voiceless if their VOT durations were over 30,40 , and $50 \mathrm{~ms}$ for $/ \mathrm{p} /$, /t/, and $/ \mathrm{k} /$, respectively. They concluded that the voicing boundary for English tokens changed along the VOT duration continuum as a function of place of articulation. They also demonstrated that VOT duration and the voicing boundary along the VOT duration continuum varied from language to language, although there were within-language regularity and cross-language predictability in the realization of voicing contrasts. In another study by Lisker et al (1977) they measured the VOT duration of several naturally-spoken utterances, comprised of /b,d,g,p,t,k/ followed by the vowel /a/. The average VOT duration of voiced plosives was found to be 1, 5, and $21 \mathrm{~ms}$ for $/ \mathrm{b} /, / \mathrm{d} /$, and $/ \mathrm{g} /$ in English, respectively. In contrast, the average VOT duration of voiceless plosives was found to be 58,70 , and $80 \mathrm{~ms}$ for $/ \mathrm{p} / \mathrm{/} / \mathrm{t} /$, and $/ \mathrm{k} / \mathrm{in}$ English, respectively. There were no values in common between voiced/voiceless pairs of plosives with the same place of articulation. Then, the VOT duration was therefore a good and easily measurable acoustic property to distinguish between voiced and voiceless plosives. According to Stevens and Klatt (1974), the VOT duration boundary between voiced and voiceless tokens was unstable and varied depending on the presence or absence of a rapidly changing F1 transition. In another experiment, Benki (2001) manipulated F1 transition, place of articulation, and VOT duration. He concluded that F1 transition and the place of articulation play an important role for voicing categorization. He also mentioned that the role of F1 transition was larger than the place of articulation. Jiang, Chen and Alwan (2006) examined the ways by which American English native speakers perceived voicing of plosives in noise. They found that this process is affected by an interaction between Signal to Noise Ratio (SNR) on the one hand, and the factors that affect the acoustic characteristics of the plosive release on the other hand; such factors include talkers' gender, place of articulation, and vowel context. Mortensen and Tøndering (2013) studied the effect of the following vowel height on VOT in Danish CV sequences with stop consonants in Danish spontaneous speech. Their results indicated a clear relationship between the vowel height and VOT of [b,d,g]. VOT was shorter when the vowels were more open. For $[\mathrm{p}, \mathrm{t}, \mathrm{k}]$, however, no significant effect of vowel height on VOT was found. In another research by Repp (1984), he studied the closure duration and release burst of stop consonants based on their manner and place of articulation. His findings show that labial stops have a longer closure interval than alveolar or velar stops. Release bursts of labial stops are weaker than alveolar and velar stops; hence the effect of burst amplitude on place of articulation perception. Byrd (1993) compared the VOT of labials and alveolars in connected read speech. Results show that alveolars have on average longer release than bilabials. The release duration increases as the point of contact moves from the lips to the velum. Whiteside and Irving (1998) studied 36 isolated words spoken by 5 men and 5 women, all in their twenties or thirties, and showed that the female speakers had on average longer VOT for voiceless plosives than the male speakers. However, it should be noted that there are also studies (Sydal, 1996) which report no significant sex difference found in VOT (as cited in Byrd, 1993: 183). Ryalls et al (2004) interestingly found significant differences between the averages VOT of the two age groups as VOT of older subjects are consistently shorter than that of younger subjects. It was also found that the average syllable duration of older subjects. Kessinger and Blumstein (1998) studied the correlation between the speaking rate and VOT. They found that VOT is negatively correlated with speaking rate and the correlation is highly significant. This fact is not surprising at all, since, intuitively, as a speaker slows down the speaking rate, all the phonetic segments would be stretched and therefore they should all show an increase in duration. In another experiment by Hoit et al (1993), they concluded that for five adult male speakers, VOT was longer when produced at high lung volumes and shorter when produced at low lung volumes (as cited in Yao, 2007: 185). 


\section{METHODOLOGY}

The data of this study are two words and their plural, which includes [t] and [d]. To pluralize the words, the suffix /-hb/ (phonetically [D]) is attached after the stem of the singular words. In singular words and their plurals, the stress occurs on the first and the second syllables, respectively. In this study, 10 subjects, with Kermani accent (5 men and 5 women) were asked to repeat each word for 3 times (table 1).

Table 1. Data of the study

\begin{tabular}{|c|c|c|c|l|}
\hline & Singular & Meaning & Plural & Meaning \\
\hline$[\mathrm{t}]$ & {$[$ 'tor] } & 'web' & {$[$ [t'ro] } & 'webs' \\
\hline [d] & {$[$ 'dor] } & 'tree' & [dD'rr] & 'trees' \\
\hline
\end{tabular}

The subjects' production was recorded by Shure microphone and the borders of the mentioned stop consonants and the following vowels were defined and labeled with the Praat phonetic analysis software (Ver. 5.3.06). Then, the VOT of the alveolar stop consonants and the amount of the F0, F1 and F2 of their following vowels was measured and compared in stressed and unstressed syllables. Comparing and measuring the dependent variables of this study, SPSS 16 and the repeated measure ANOVA were used.

\section{VARIABLES}

\subsection{Dependent Variables}

The dependent variables of this study are quantitative and they have been measured to determine the effect of the independent variables on them. The dependent variables of this study are:

\subsubsection{VOT}

VOT is defined as the interval between cursors placed at the onset of release and the onset of the first complete vibration of the vocal folds as indicated on the waveform (Cho and Ladefoged, 1999).

\subsubsection{FO}

Lehiste (1970) found that there appears to be a physiological reason for the fact that high vowels are of higher fundamental frequency than low ones. Fundamental frequency increased with either increased rate of the vocal folds or increased rate of airflow (or a combination of both). In the articulation of high vowels, the tongue is raised toward the roof of the mouth. Now the muscles constituting the tongue are attached to the superior part of the hyoid bone, and some of the laryngeal muscles are attached to the inferior part. Raising of the tongue caused the larynx to be pulled upwards and the laryngeal muscles are stretched. These movements increase the tension of the vocal folds, by which the rate of vibration increased automatically. He also illustrated that higher fundamental frequencies occurred after a voiceless consonant and considerably lower fundamental frequencies occurred after a voiced consonant.

\subsubsection{F1 and F2}

Lindblom (1963) created some nonsense words using /I, $\varepsilon, \mathrm{Y}, \propto, \mathrm{a}, \theta, \mathrm{c}, \mathrm{v} / \mathrm{in}$ environment of $/ \mathrm{d}-\mathrm{d} / \mathrm{/} / \mathrm{b}-\mathrm{b} / \mathrm{and} / \mathrm{g}-\mathrm{g} / \mathrm{in}$ Swedish language; and investigated the influence of stress on those mentioned vowels. The results of his research showed that the vowels were reduced in unstressed syllables and approximated to centeral vowel /ə/. This effect on F2 was obvious and he called this process "undershoot". Gu, Mori and Kasuya (2003) proved that vowel reduction caused reduction of $\mathrm{F} 1$ in /a/ in Mandarin language. They believe that the space between the jaws in focused state, while articulating this vowel, was more compared to their space in normal position. Mooshammer and Geng (2008) studied/y, e, $œ, a, o, u, i /$ of German language, in stressed syllables and unstressed syllables in CVC and compared them with lingual positions for combined effects of stress, accent and corrective contrasts. Results showed a great degree of coarticulation with the consonant context for unstressed vowels compared to stressed ones. He illustrated that, in vowel reduction process, F2 in front vowels decreased and in back vowels increased. In addition, vowel shortening only occurred for tense vowels, whereas lax vowels were reduced without shortening.

\subsection{Independent Variables}

This qualitative kind of variables are those over which the researcher has no control. In this research the independent variables are:

\subsubsection{Stressed syllable}


Stressed syllables are articulated with more articulatory effort in the respiratory system and increase of vocal folds tension which makes sounds of higher pitch (Ladefoged and Johnson, 2011). A syllable is stressed whenever there is some change in its fundamental frequency, amplitude and duration. The most effective factors for a stressed syllable are fundamental frequency, amplitude and duration respectively (Lieberman, 1960).

\subsubsection{Unstressed syllable}

Unstressed syllables, in comparison with stressed syllables, are articulated with less articulatory effort. Vowels of unstressed syllables are similar to central vowels. In stressed syllables, the duration of vowels and consonants is more than unstressed syllables (Lehiste, 1997).

\subsubsection{Voiced}

Sounds produced when the vocal folds are vibrating are said to be voiced (Ladefoged and Johnson, 2011).

\subsubsection{Voiceless}

Sounds pronounced without vibrations of the vocal folds are voiceless ones (Ladefoged and Johnson, 2011).

\section{DATA ANALYSIS}

\subsection{Descriptive statistics}

\subsubsection{VOT}

\subsubsection{Mean VOT of [t] in stressed and unstressed syllables}

In table 2, the mean VOT of [t] in stressed and unstressed syllables, is shown.

Table 2. Mean VOT of [t] in stressed and unstressed syllables

\begin{tabular}{|c|c|c|c|c|}
\hline & \multirow{2}{*}{ Mean } & Standard deviation & \multicolumn{2}{|c|}{$95 \%$ confidence interval } \\
\cline { 4 - 5 } & & & Lower bound & Upper bound \\
\hline Stressed & 78.07 & 5.14 & 67.49 & 88.66 \\
\hline Unstressed & 62.38 & 4.21 & 53.72 & 71.05 \\
\hline
\end{tabular}

According to this table, the mean VOT of [t] in stressed syllables is more than that in unstressed syllables.

\subsubsection{Mean VOT of [d] in stressed and unstressed syllables}

Table 3 give some information about the mean VOT of [d] in stressed and unstressed syllables.

Table 3. Mean VOT of [d] in stressed and unstressed syllables

\begin{tabular}{|c|c|c|c|c|}
\hline & \multirow{2}{*}{ Mean } & Standard deviation & \multicolumn{2}{|c|}{$95 \%$ confidence interval } \\
\cline { 3 - 5 } & & & Lower bound & Upper bound \\
\hline Stressed & 0.04 & 9.2 & -18.91 & 18.98 \\
\hline Unstressed & -9.731 & 13.025 & -36.55 & 17.1 \\
\hline
\end{tabular}

Based on the above information, the mean VOT of [d] in stressed positions is more than that in unstressed positions.

\subsubsection{FO}

\subsubsection{The mean FO of $[\mathrm{D}]$ in stressed and unstressed syllables}

Table 4 shows the mean F0 of [D] in stressed and unstressed syllables. 
Table 4. The mean F0 of [D] in stressed and unstressed syllables

\begin{tabular}{|c|c|c|c|c|}
\hline & \multirow{2}{*}{ Mean } & Standard deviation & \multicolumn{2}{|c|}{$95 \%$ confidence interval } \\
\cline { 4 - 5 } & & & Lower bound & Upper bound \\
\hline Stressed & 192.02 & 11.87 & 167.56 & 216.48 \\
\hline Unstressed & 169.34 & 10.7 & 147.3 & 191.39 \\
\hline
\end{tabular}

According to this table, it is obvious that the F0 of [p] in stressed syllable is more than that in unstressed syllables.

\subsubsection{The mean FO of [D] following voiced and voiceless alveolar stops.}

Table 5 shows the effect of [voice] feature on the F0 of [o], which is occurred after the voiced and voiceless alveolar consonants.

Table 5. The mean F0 of [p] following voiced and voiceless alveolar stops

\begin{tabular}{|c|c|c|c|c|}
\hline & \multirow{2}{*}{ Mean } & \multirow{2}{*}{ Standard deviation } & \multicolumn{2}{|c|}{$95 \%$ confidence interval } \\
\cline { 4 - 5 } & & & Lower bound & Upper bound \\
\hline [t] & 186.67 & 10.7 & 164.6 & 208.7 \\
\hline [d] & 174.67 & 11.5 & 151 & 198.3 \\
\hline
\end{tabular}

The F0 of [D] after the voiced alveolar consonant is more than that after the voiceless one.

\subsection{3. $F 1$}

\subsubsection{The mean $F 1$ of $[D]$ in stressed and unstressed syllables}

Based on table 6 , the mean $\mathrm{F} 1$ of [D] in stressed syllables is more than that in unstressed syllables.

Table 6. The mean $\mathrm{F} 1$ of $[\mathrm{p}]$ in stressed and unstressed syllables

\begin{tabular}{|c|c|c|c|c|}
\hline & \multirow{2}{*}{ Mean } & \multirow{2}{*}{ Standard deviation } & \multicolumn{2}{|c|}{$95 \%$ confidence interval } \\
\cline { 4 - 5 } & & & Lower bound & Upper bound \\
\hline Stressed & 677.19 & 11.63 & 653.23 & 701.15 \\
\hline Unstressed & 665.77 & 10.05 & 645.08 & 686.46 \\
\hline
\end{tabular}

\subsubsection{2.}

The mean $\mathrm{F} 1$ of [D] following voiced and voiceless alveolar stops

In table 7 , the mean $\mathrm{F} 1$ of [D] after voiced and voiceless alveolar consonants is indicated.

Table 7. The mean F1 of [D] following voiced and voiceless alveolar stops

\begin{tabular}{|c|c|c|c|c|}
\hline \multirow{2}{*}{} & \multirow{2}{*}{ Mean } & Standard deviation & \multicolumn{2}{|c|}{$95 \%$ confidence interval } \\
\cline { 4 - 5 } & & & Lower bound & Upper bound \\
\hline [t] & 689.6 & 10.6 & 667.81 & 711.37 \\
\hline [d] & 653.36 & 11.34 & 630 & 676.72 \\
\hline
\end{tabular}


As it is shown, after [t], the mean $\mathrm{F} 1$ of $[\mathrm{b}]$ is more than that when following [d].

\subsubsection{F2}

\subsubsection{The mean F2 of [D] in stressed and unstressed syllables}

As it is indicated in table 8, the mean $\mathrm{F} 2$ of [D] vowel in unstressed positions is more than that in unstressed positions.

Table 8. The mean F2 of [p] in stressed and unstressed syllables

\begin{tabular}{|c|c|c|c|c|}
\hline & \multirow{2}{*}{ Mean } & \multirow{2}{*}{ Standard deviation } & \multicolumn{2}{|c|}{$95 \%$ confidence interval } \\
\cline { 4 - 5 } & & & Lower bound & Upper bound \\
\hline Stressed & 1250.5 & 16.23 & 1217 & 1283.94 \\
\hline Unstressed & 1279.61 & 17.94 & 1242.66 & 1316.56 \\
\hline
\end{tabular}

\subsubsection{2.}

The mean F2 of [D] following voiced and voiceless alveolar stops

In the following table, the mean $\mathrm{F} 2$ of [D] in stressed and unstressed syllables are shown.

Table 9. The mean F2 of [D] following voiced and voiceless alveolar stops

\begin{tabular}{|c|c|c|c|c|}
\hline \multirow{2}{*}{ Mean } & \multirow{2}{*}{ Standard deviation } & \multicolumn{2}{|c|}{$95 \%$ confidence interval } \\
\cline { 4 - 5 } & & & Lower bound & Upper bound \\
\hline [t] & 1236.27 & 17.24 & 1200 & 1271.61 \\
\hline [d] & 1293.85 & 15.91 & 1261 & 1326.61 \\
\hline
\end{tabular}

This table shows that the mean F2 of vowels following $[\mathrm{d}]$ is more than those following [t].

\subsection{Analytic statistics}

\subsubsection{VOT}

\subsubsection{VOT of [t] in stressed and unstressed syllables}

Based on table 10 and the repeated measure ANOVA test, the effect of stress on the VOT of $[t]$ is significant $(P=0.000)$.

Table 10. The results of comparing the mean VOT of $[t]$ in stressed and unstressed syllables

\begin{tabular}{|l|c|c|c|c|c|}
\hline & Type III sum of squares & df & Mean square & F & Sig. \\
\hline Stress & 3201.23 & 1 & 3201.231 & 22.992 & 0.000 \\
\hline
\end{tabular}

Also the post-hoc Bonferroni test shows that the mean VOT of [t] in stressed syllables is $15.692 \mathrm{~ms}$ more than that in unstressed syllables.

\subsubsection{VOT of [d] in stressed and unstressed syllables}

Based on the repeated measure ANOVA test, the effect of stress on the VOT of [d] is not significant $(P=0.264)$.

Table 11. The results of comparing the mean VOT of [d] in stressed and unstressed syllables

\begin{tabular}{|l|c|c|c|c|c|}
\hline & Type III sum of squares & df & Mean square & F & Sig. \\
\hline Stress & 1240.67 & 1 & 1240.67 & 1.305 & 0.264 \\
\hline
\end{tabular}


According to table 11, in stressed position, the VOT of [d] is 9.769 ms more than that in unstressed syllables (based on the post-hoc Bonferroni test).

\subsection{2. $F O$}

\subsubsection{The mean FO of vowels in stressed and unstressed syllables}

According to table 12 and based on the repeated measure ANOVA test the effect of stress on the F0 of vowels is significant $(P=0.001)$.

Table 12. The results of comparing the mean F0 of vowels in stressed and unstressed syllables

\begin{tabular}{|l|c|c|c|c|c|}
\hline & Type III sum of squares & $\mathbf{d f}$ & Mean square & $\mathbf{F}$ & Sig. \\
\hline Stress & 13365.8 & 1 & 13365.8 & 13.75 & 0.001 \\
\hline
\end{tabular}

The post-hoc Bonferroni test shows that the F0 of vowels in stressed syllables is $22.673 \mathrm{~Hz}$ more than in unstressed syllables.

\subsubsection{The mean FO of vowels following voiced and voiceless alveolar stops}

The repeated measure ANOVA shows that the effect of [Voice] feature on the F0 of the following vowel is significant $(\mathrm{P}=0.012)$.

Table 13. The results of comparing the mean F0 of vowels following voiced and voiceless alveolar stops

\begin{tabular}{|l|c|c|c|c|c|}
\hline & Type III sum of squares & df & Mean square & F & Sig. \\
\hline Voice & 3756 & 1 & 3756 & 7.43 & 0.012 \\
\hline
\end{tabular}

The post-hoc Bonferroni test shows that the F0 of vowels following [+voiced] consonants is $12.02 \mathrm{~Hz}$ less than those following [-voiced] consonants.

\subsection{3. $F 1$}

\subsubsection{The mean F1 of vowels in stressed and unstressed syllables}

As it is obvious in table 15, the effect of stress on the F1 of the vowels is not significant.

Table 15. The results of comparing the mean F1 of vowels in stressed and unstressed syllables.

\begin{tabular}{|l|c|c|c|c|c|}
\hline & Type III sum of squares & $\mathbf{d f}$ & Mean square & F & Sig. \\
\hline Stress & 3392.65 & 1 & 3392.65 & 2.238 & 0.147 \\
\hline
\end{tabular}

The results of the post-hoc Bonferroni test show that the $\mathrm{F} 1$ of [o] in stressed syllables is $11.423 \mathrm{~Hz}$ more than that in unstressed syllables.

\subsubsection{The mean F1 of vowels following voiced and voiceless alveolar stops}

According to table 16 and the repeated measure ANOVA, the effect of [voice] feature on the F1 of the following vowel is significant $(P=0.000)$.

Table 16. The results of comparing the mean F1 of vowels following voiced and voiceless alveolar stops

\begin{tabular}{|l|c|c|c|c|c|}
\hline & Type III sum of squares & df & Mean square & F & Sig. \\
\hline Voice & 34129.38 & 1 & 34129.38 & 19.65 & 0.000 \\
\hline
\end{tabular}

According to the post-hoc Bonferroni test, the $\mathrm{F} 1$ of the vowels following the voiceless alveolar consonants, is $36.231 \mathrm{~Hz}$ more than those following the voiced ones. 


\subsubsection{F2}

\subsubsection{The mean F2 of vowels in stressed and unstressed syllables}

According to table 18 and based on the repeated measure ANOVA, the effect of stress on the $\mathrm{F} 2$ of $[\mathrm{D}]$ is significant $(\mathrm{P}=$ 0.066).

Table 18. The results of comparing the mean $\mathrm{F} 2$ of vowels in stressed and unstressed syllables.

\begin{tabular}{|l|c|c|c|c|c|}
\hline & Type III sum of squares & df & Mean square & F & Sig. \\
\hline Stress & 22040.34 & 1 & 22040.34 & 3.707 & 0.066 \\
\hline
\end{tabular}

Post-hoc Bonferroni test shows that the F2 of [o] in stressed syllables is $29.115 \mathrm{~Hz}$ less than that in unstressed syllables.

\subsubsection{The mean F2 of vowels following voiced and voiceless alveolar stops}

According to table 19, it is obvious that the effect of the [voice] feature on the $F 2$ of the following vowel is significant $(P=$ 0.000).

Table 19. The results of comparing the mean $\mathrm{F} 1$ of vowels following voiced and voiceless alveolar stops

\begin{tabular}{|c|c|c|c|c|c|}
\hline & Type III sum of squares & df & Mean square & F & Sig. \\
\hline Voice & 86192.65 & 1 & 86192.65 & 20.93 & 0.000 \\
\hline
\end{tabular}

The post-hoc Bonferroni test indicates that the F2 of [D] following [d] is $57.577 \mathrm{~Hz}$ more than that following [t].

\section{CONCLUSION}

This study shows that in Kermani accent, the mean VOT of [t] and [d] in stressed position is more than that in unstressed positions. Unlike F2, F0 and F1 of vowels following [t] and [d] in stressed syllables are more than those in unstressed syllables. This is the result of the process of vowel reduction in Kermani accent. Also F0 and F1 of vowels following [+voiced] alveolar stops are less than those following [-voiced] alveolar stops.

\section{REFERENCE}

[1] AIDahri, S., S. 2013. A study for the effect of the Emphaticness and language and dialect for Voice Onset Time (VOT) in Modern Standard Arabic (MSA).arXiv preprint arXiv, 11-29.

[2] Benkí, J. R. 2001. Place of articulation and first formant transition pattern both affect perception of voicing in English. Journal of Phonetics, 29(1), 1-22

[3] Byrd, D. 1993. 54,000 American stops. UCLA Working Papers in Phonetics, 83, 97-116.

[4] Cho, T. and Ladefoged, P. 1999. Variation and universals in VOT: evidence from 18 languages. Journal of Phonetics, 27(2), 207-229.

[5] Fischer-Jørgensen, E. 1954. Acoustic analysis of stop consonants. Miscellanea Phonetica, 2, 42-59.

[6] Gu, Z, Mori, H. and Kasuya, H. 2003. Analysis of vowel formant frequency variations between focus and neutral speech in Mandarin Chinese. Acoustical Science and Technology, 24(4), 192-193.

[7] Hardcastle, W. J. 1973. Some observations on the Tense-Lax distinction in initial stops in Korean. Journal of phonetics, 1, 263-271.

[8] Hoit, J. D., Solomon, N. P. and Hixon, T.J. 1993. Effect of lung volume on voice onset time (VOT). Journal of Speech, Language, and Hearing Research, 36(3), 516-520.

[9] Jiang, J., Chen, M. and Alwan, A. 2006. On the perception of voicing in syllable-initial plosives in noisea. The Journal of the Acoustical Society of America, 119(2), 1092-1105.

[10] Kessinger, R. H. and Blumstein, S. E. 1998. Effects of speaking rate on voice-onset time and vowel production: Some implications for perception studies. Journal of Phonetics, 26(2), 117-128.

[11] Ladefoged, P. and Johnson, K. 2011. A course in phonetics. Cengage learning.

[12] Lehiste, I. 1970. Suprasegmentals. Massachessettes: The M.I.T press. 
[13] Lehiste, I. 1997. Search for phonetic correlates in Estonian prosody. In Estonian Prosody: Papers from a Symposium. 11-35.

[14] Lieberman, P.1960. Some acoustic correlates of word stress in American English. The Journal of the Acoustical Society of America, 32(4), 451-454.

[15] Lindblom, B. 1963. Spectrographic Study of Vowel Reduction. Journal of the Acoustical Society of America, 35 (11), 1773-1778.

[16] Lisker, L. and Abramson. A. S. 1964. A cross-language study of voicing in initial stops: Acoustical measurements. Word, 20(3), 384-422.

[17] Lisker, L. and Abramson, A. S. 1970. The voicing dimension: Some experiments in comparative phonetics. In Proceedings of the 6th international congress of phonetic sciences, 563, 563-567.

[18] Lisker, L., Liberman, A. D., Erickson, D. M., Dechovitz, D. and Mandler, R. 1977. On pushing the voice-onset-time (VOT) boundary about. Language and Speech, 20(3), 209-216.

[19] Mooshammer, C. and Geng, C. 2008. Acoustic and articulatory manifestations of vowel reduction in German. Journal of the International Phonetic Association, 38(02), 117-136.

[20] Mortensen, J. and Tøndering, J. 2013. The effect of vowel height on Voice Onset Time in stop consonants in CV sequences in spontaneous Danish. Proceedings of Fonetik 2013, The XXVIth Annual Phonetics Meeting, 49-52.

[21] Repp, B. H. 1984. Closure duration and release burst amplitude cues to stop consonant manner and place of articulation. Language and speech, 27(3), 245-254.

[22] Ryalls, J., Simon, M. and Thomason, J. 2004. Voice onset time production in older Caucasian-and AfricanAmericans. Journal of Multilingual Communication Disorders, 2(1), 61-67.

[23] Stevens, K. N., Keyser, S. J. and Kawasaki, H. 1986. Toward a phonetic and phonological theory of redundant features. Invariance and variability in speech processes, 426-449.

[24] Stevens, K. N. and Klatt, D. H. 1974. Role of formant transitions in the voiced-voiceless distinction for stops. The Journal of the Acoustical Society of America, 55(3), 653-659.

[25] Sydal, A. K. 1996. Acoustic Variability in spontaneous conversational speech of American English talkers. Proceeding of ICSLP 96, 438-441.

[26] Whiteside, S. P. and Irving, C.J. 1998. Speakers' sex differences in voice onset time: A study of isolated word productions. Perceptual and motor skills, 85, 2, 651-654.

[27] Yao, Y. 2007. Closure duration and VOT of word-initial voiceless plosives in English in spontaneous connected speech. UC Berkeley Phonology Lab Annual Report, 183-225.

\section{Author' biography}

Vahideh Abolhasanizadeh

Assistant Professor of Shahid Bahonar University of Kerman, Department of foreign languages, faculty of literature and humanities, Shahid Bahonar university of Kerman, Pazhuhesh square, Kerman, 7616914111, Iran

vahidehabolhasani@yahoo.com

Anis Masoumi

M.A student of Allame Tabataba'i University of Tehran

anis masoumi@yahoo.com 